\title{
Experimental investigation of infrared signal characteristics in a micro-turbojet engine - ERRATUM
}

doi:10.1017/aer.2018.164, first published online on 5 April 2019.

The above article was published with an incorrect author name.

The correct authors are S. M. Choi, S. Kim, R. S. Myong and W. Kim - not S. M. Choi, S. Myong, R. S. Myong and W. Kim as published.

Cambridge University Press apologises for this error and any inconvenience it may have caused.

\section{REFERENCE}

Choi, S., Myong, S., Myong, R. and Kiм, W. Experimental investigation of infrared signal characteristics in a micro-turbojet engine. The Aeronautical Journal, 2019, 123(1261), 340-355, 10.1017/ aer.2018.164. 